\title{
Erratum to: No effect of menstrual cycle phase on glucose and glucoregulatory endocrine responses to prolonged exercise
}

\author{
Robert R. Kraemer - Michelle Francois • Nancy Dardis Webb • Jennifer R. Worley •
}

Sharon N. Rogers • Reid L. Norman • Urvi Shah • V. Daniel Castracane

Published online: 25 July 2013

(c) Springer-Verlag Berlin Heidelberg 2013

\section{Erratum to: Eur J Appl Physiol}

DOI 10.1007/s00421-013-2677-9

Unfortunately, the given and family names of the last author were incorrectly published in the original version. The correct author's name should read as V. Daniel Castracane.

The online version of the original article can be found under doi:10.1007/s00421-013-2677-9.

R. R. Kraemer $(\bowtie) \cdot$ M. Francois · N. D. Webb .

J. R. Worley · S. N. Rogers

Department of Kinesiology and Health Studies, Southeastern

Louisiana University, SLU10845, Hammond, LA 70402, USA

e-mail: rkraemer@selu.edu

R. L. Norman

Department of Pharmacology and Neuroscience, Texas Tech

University Health Sciences Center, Lubbock, TX, USA

U. Shah · V. D. Castracane

Department of Obstetrics and Gynecology, Texas Tech

University Health Sciences Center at the Permian Basin,

Odessa, TX, USA 